\title{
THERAPY FOR A GROUP OF TONGUE THRUST SWALLOWERS AND THEIR MOTHERS
}

\author{
NIGEL BLIGH B.A. LOG. (Rand), M.A. (Rand) \\ Department of Speech Pathology \& Audiology, * \\ University of the Witwatersrand, Johannesburg
}

\section{SUMMARY}

A brief description of tongue thrusting and associated problems is given. The therapy programme for a group of tongue thrusting children and their mothers is described. Traditional swallow retraining was used with the group of children in conjunction with exercises for strengthening and increasing oro-sensory awareness of tongue and lips. A therapist guided the mothers' discussions while they observed therapy. Results indicated that therapy was successful. The conclusions suggest further avenues of research.

\section{OPSOMMING}

'n Kort beskrywing van infantiele slukpatroon en verwante probleme word gegee.

Die terapieprogram vir 'n groep kinders met infantiele slukpatroon en hul moeders word beskryf. Tradisionele slukheropleiding is gebruik met hierdie groep kinders tesame met oefeninge vir die versterking en verhoging van orosensoriese bewustheid van die tong en lippe.

'n Terapeut het die moeders se besprekings gelei terwyl hulle terapie waargeneem het. Resultate het daarop gedui dat terapie suksesvol was. Die gevolgtrekkings bied verdere kidrade vir navorsing.

One of the perennial problems the speech therapist shares with the orthodontist is the tongue thruster. On the surface this appears a simple difficulty to correct. It is however, extraordinarily resistant to therapy. This article will discuss some relevant problems and a suggested therapy programme.

\section{SYMPTOMS AND PROBLEMS ASSOCIATED WITH TONGUE THRUST}

\section{Incorrect Swallow Pattern}

The classification of simple, complex and retained infantile swallow ${ }^{3}$, will be disregarded as it is irrelevant to the rehabilitation programme. The main identifying feature is a forward movement of the tongue, generally against or between the teeth, during swallowing, with deviant usage of several muscle groups, e.g. supra and infrahyoid, masseter, temporalis, and orbicularis oris. ${ }^{10}$

* Now at 626 E. Minnehaha Parkway, Minneapolis, Minn. 55417, USA. 
Movement of the lips and contraction of the muscles of mastication are often evident during swallowing as a lip-seal is used instead of a tongue/palate seal. ${ }^{18}$ The individual resists attempts to part the lips during a swallow.

\section{Effect on Orofacial Structure}

As a result of regular incorrect pressure of the tongue on the teeth ${ }^{3}$ and the added pressure of the muscles of deglutition, mandibular growth and natural dental alignment may be affected. ${ }^{15}$ Top and occasionally, bottom teeth may protrude. Irregular spacing is not uncommon. The type of dental involvement will depend on the nature of the incorrect swallow. The malocclusion may prevent a natural relaxed position of the mouth at rest, so that the lips will not exert the optimal pressure necessary for facial development. The loss of regular pressure may lead to a high vaulted palate. ${ }^{11,15}$ There appears to be loss of tone and strength in the lips and tongue. $1,10^{*}$ Individuals who swallow incorrectly seem to have excessive muscle activity and develop muscle patterns that are not as clearcut or definite as those of normal swallowers. ${ }^{10}$

\section{Medical History}

Tongue thrusters often have a history of tonsil, adenoid and respiratory involvement, which can lead to other problems associated with tongue thrust, ${ }^{17}$ i.e. chronic mouth breathing, either from necessity or habit. This in turn causes a tongue rest position with tongue tip away from the alveolar ridge. ${ }^{3}$

\section{Sucking Problems}

There is not infrequently a problem of sucking as a baby. It has been suggested that nipples that allow the milk to flow too freely lead to incorrect swallowing. ${ }^{15}$ Thumb and finger sucking is common, accentuating dental misalignment ${ }^{9}$, and incorrect swallow patterns. ${ }^{3}$

\section{Speech}

A study by Fletcher $e t a l^{4}$ found a relationship between tongue thrust swallowing pattern and sibilant distortion. Although not automatically involved, typically speech has tip-dental production of tip-alveolar sounds. ${ }^{3,10}$ Speech will often be accoustically acceptable but visually unacceptable.

\section{Therapy}

Therapy for tongue thrust given either by the orthodontist or speech therapist, is frequently described in the literature. $3,6,10,16,18$ It involves basically either the re-training of the musculature involved in swallowing, or the use of a habit-breaker appliance. Results are often equivocal. One of the main difficulties would appear to be the evocation of adequate motivation to form new habits. ${ }^{6,15}$

\footnotetext{
* Confirmed in personal communication with Dr C. Overstake.
} 


\section{Additional Unverified Observations}

(i) There is an impression of lowered kinaesthetic and orosensory awareness, e.g. tolerance to extremes of temperature, inability to move the tongue accurately on demand ${ }^{18}$, and difficulty in moving the tongue without concomitant lip and jaw movements.

(ii) The difficulty seems to be commoner amongst girls than boys. Of sixteen tongue thrusters receiving therapy at the Speech \& Hearing Clinic, University of the Witwatersrand, five were boys. In a study by Mims et al ${ }^{9}$ discussing the relationships between thumb sucking and open-bite malocclusions, there were 24 boys and 52 girls.

(iii) There seems to be a familial tendency to tongue thrust. ${ }^{13}$

\section{METHOD}

The aims of the study were (a) to investigate an approach to therapy for tongue thrusters, (b) to investigate certain aspects of group therapy, i.e. group size, age range and variation in therapist, and (c) to explore a method of parent counselling.

\section{GROUP THERAPY PROGRAMME}

\section{Subjects}

There were six girls and three boys ranging in age from four and a half to eleven years. The four and a half-year old was taken despite evidence in the literature ${ }^{14}$ that tongue thrusting is a normal developmental stage because his . teeth were already being pushed out of alignment and there was a definite familial tendency. This familial tendency was noted in the two sets of siblings in the group and two of the other children. Five of the children were being seen for individual articulation therapy once a week, in addition to the weekly group therapy for tongue thrust. Because it was a group project, it was unnecessary to eliminate those children who did not have speech defects purely because this was a speech clinic. ${ }^{17}$ It will be noted that both the size of the group and the age range, are in conflict with most of the recommendations in the literature. 8

\section{Therapists}

One graduate therapist and six speech and hearing therapy students at the University of the Witwatersrand participated in the weekly group therapy. The student therapists were involved in individual articulation therapy for tongue thrusters on a second afternoon. Initially the graduate therapist took the group with the students observing. Therapists then alternated as group leader with the others observing and later participating. After each session there was a seminar to discuss the therapy'administered and plan the following week's session. The effects on the group of alternating therapists were noted throughout. 


\section{Therapy Aims}

1. To eliminate any causal or maintaining factors of tongue thrust.

2. To explain to the children why they were coming for therapy and to generate motivation.

3. To correct the swallow pattern.

4. To correct the rest position of tongue and lips.

5. To increase proprioception, kinesthesia, tone and strength of tongue and lips.

\section{Therapy Procedures}

Throughout therapy all drill work and explanations were presented in a suitably motivating and understandable fashion.

1. All children were under observation by orthodontists. Four of them had been referred for therapy before orthodontics would be attempted. Three children were encouraged to stop sucking their thumbs and one had his tonsils and adenoids removed.

2. (a) The children learnt that they were exerting $1 \frac{1}{2}$ lbs of thrust on their teeth 2000 times a day, i.e. each time they swallowed ${ }^{3,11}\left(\right.$ Ehrlich $^{3}$ mentions $^{2}$ $6 \mathrm{lbs})$. The children were encouraged to discuss what effect this would have on their looks.

(b) They learnt the hygienic reasons for breathing through their noses rather than through their mouths.

(c) They were taught that with better control and proprioceptive awareness of their lips and tongues they would be better able to place them where they wanted to and keep them there.

3. The following rules were learnt (Overstake ${ }^{10}$ ):-

(a) Put your teeth and lips lightly together.

(b) Place the tip of your tongue on the alveolar ridge.

(c) Suck the food onto your tongue.

(d) Then push your tongue onto your palate and swallow.

(e) Your tongue must not move forward.

4. There were intermittent reminders for the children to "look nice and feel nice", i.e. to have their mouths shut and tongue tips resting lightly on the alveolar ridges.

5. Tongue and lip therapy was divided into:

(a) Movement - lips were spread and pursed as in an exaggerated "oo-ee". Tongue was moved sideways, in and out, up and down. Instructions were given to place the tongue in specific positions. The main aim was to get independent tongue movement, i.e. without concomitant lip and jaw movement and to achieve better awareness of tongue position in the mouth.

(b) Icing is a technique advocated by physiotherapists and speech therapists working with cerebral palsied children. Used for any length of time ice acts as an anaesthetic. For shorter periods it seems in most cases to 
encourage relaxation, 7,12 increases the blood supply to the surface areas and encourages increased proprioceptive awareness. Empirical use indicates that it is a useful technique to use in articulation therapy. With this group it was used in conjunction with resistance exercises.

(c) Resistance is a technique for strengthening and improving coordination of muscles. ${ }^{7}$ The amount of resistance offered must never be greater than the muscle strength, i.e. the individual must always be able to complete the movement. Resistance should obviously increase as the muscle gets stronger.$^{5,12}$ The children's tongues or lips were iced and the following resistance exercises were then done:-*

i) As the child protruded the tongue the tip was gently resisted by the therapist or by another child holding a wooden spatula.

ii) The child moved the tongue towards one side while movement was resisted with the spatula from the other.

iii) The child elevated or depressed the tongue tip with resistance from the other direction. This generally required two spatulas, one above the tongue to aid movement, and one below to resist, and vice versa. Assistance was necessary for those children who had difficulty elevating or depressing the tongue.

iv) Lip movement was gently resisted by the therapists' fingers held at each corner of the mouth, as the child spread or pursed his lips. At the end of each session the children were given a home programme to encourage carry-over of all therapy activities. A resistance technique that may be worth investigating, especially for swallow retraining, is the use of a $1 / 2$, cube of sponge rubber securely attached to a cord that the therapist pulls to resist the tongue motion while swallowing. ${ }^{7}$

\section{COUNSELLING PROGRAMME}

Six mothers were counselled regularly and one irregularly. The aims were to explain the rationale behind therapy, and to motivate parents to carry on with the programme at home. Initially the mothers were counselled briefly and given the week's home programme after the group therapy by the graduate therapist with the students observing. Subsequently the mothers observed the entire therapy session through a one-way mirror with therapists taking it in turn to guide observation and discussion. The children were all aware of the fact that their mothers were observing.

The discussion revolved around the nature of tongue thrust and the associated problems, what therapy was aiming at and the difficulties inherent in treating the problem. As therapy progressed, discussion of different approaches, techniques and reactions of the various children were encouraged.

\footnotetext{
* Adapted from suggestions by Miss J. Blair, Head of the Dept. of Physiotherapy, University of the Witwatersrand.
} 


\section{RESULTS AND DISCUSSION}

By the very nature of the disorder and its prognosis, tongue thrust therapy has a tendency to be both dull and rather discouraging. ${ }^{3}$ It is difficult to alter oral patterns that are so closely related to reflexes. ${ }^{18}$

\section{Tongue Thrust Therapy}

In therapy all children showed a definite improvement in the manner of swallowing, and the elimination of concomitant problems, i.e. mouth breathing, thumb sucking, etc. There was a consistent improvement in articulation. The mothers reported an increased awareness of the problem and its associated difficulties. All reported good carry-over during therapy. There was a definite but incomplete regression when regular therapy stopped, due to university examinations.

For this reason all the children were reterred to the Dental Clinic of the University of the Witwatersrand to be fitted with habit breaker plates. Dental impressions and X-Rays were taken and the children were given simple plates with exaggerated rugae to remind them of the correct tongue tip position. These were to be worn during the break from the rapy. In view of the therapy the children had had, it was felt unnecessary to make use of any type of grid to prevent forward movement of the tongue. ${ }^{13,15}$ During the therapist discussions, it was suggested that the use of straws for drinking ${ }^{11}$ did not assist the tongue in the correct movement for swallowing, but in fact, tended to encourage both a forward tongue movement and an excess of movement in the orbicularis oris. It was therefore discontinued as a therapy tool.

\section{Group Therapy}

The children enjoyed therapy and co-operated well. It was found that activities that fostered movement and laughter were more successful than others and resulted in better group cohesion. The large number in the group proved entirely satisfactory and manageable and made several of the activities more feasible. Even though therapy was geared to a very physical level, personality changes were evident, e.g. the shyer children became more open and the rather sophisticated child became more pleasingly child-like. One of the older girls, who was resistant to all previous attempts to deal with her problem benefitted from the opportunity to share a common experience with the others. Not only did she see that there were several other children in the same position, but she also soon became a leader in the group.

The age range proved to be an advantage in that the older children were not only encouraged to assist the younger ones, but in fact did a great deal to help them. The potential danger that the older children would dominate the younger ${ }^{8}$ was not realised. It was however, evident that the group had to be confined to primary school children. Because of the disparity of abilities, it was found to be important to eliminate any element of competition and to 
concentrate on co-operation. ${ }^{2}$ This meant that the therapist had to be very perceptive to the reactions of the children both to each other and to their own achievements.

The therapy programme was aimed mainly at providing guidance for the home programmes, i.e. therapy was not merely thirty minutes of drill to be forgotten until the next week. Thus all homework activities grew out of the preceding session or led logically towards the next. It did not seem to be important to the children that the therapist varied from session to session. It was almost as though the important inter-relationships were inter-child relationships and the therapist was there mainly to guide activities. The therapists found therapy entertaining and challenging. The discussions after each session ensured continuity and resulted in some novel and stimulating ideas and an ever improving therapeutic approach.

\section{Parent Counselling}

The parents were an integral part of the therapy programme. They knew exactly what their children were doing in therapy and why they were doing it. They became interested in the whole programme and accepted the fact that prognosis was not very good. They were receptive to any new approaches that were tried.

The therapists felt that the interest shown by the mothers contributed to the excellent attendance, the fact that homework was always done and to the general positive attitude to therapy.

Additional positive effects of this form of counselling were:

(a) The mothers saw how the therapists handled the children.

(b) Parents often spontaneously noted factors about their children that led to greater objectivity and greater reception to therapist suggestions.

(c) The group discussion often revolved around an incident in therapy that did not necessarily involve tongue thrusting but was relevant to the child. For optimal effectiveness, this type of approach required two therapists - one with the children and one guiding the parent discussions.

\section{CONCLUSIONS}

It was felt generally that this approach to therapy with tongue thrusters was successful in that both mothers and children were motivated to work on the problem. Overall results were most encouraging. Ideas were generated that might lead to better carry-over and, finally, total rehabilitation. These included:

1. Planning the programme so that therapy could gradually be terminated to ensure complete rehabilitation. 
2. Using dental study models and X-Rays before and after therapy not only as an objective measure of progress but also as a motivating force and an excellent means of explaining the problem.

3. Investigating different types of habit breakers and using them in conjunction with the therapy programme.

4. Developing the home programme further, extending this to a more active participation by the teacher and the group at the school.

5. Investigating the use of aids such as straws, in correcting swallowing patterns.

The group therapy techniques were successful and could be applied with advantage to other problems. In fact it would be interesting to investigate whether factors such as large grcup size, identification with one therapist, etc., would be as apparently insignificant with a group of children whose problem was more psychological.

General investigations into the factors contributing towards general cohesion in group therapy for speech defectives may well be rewarding.

The method of counselling mothers would probably be excellent for other difficulties especially where a greater understanding of therapeutic approach and handling of the children is required.

\section{ACKNOWLEDGEMENT}

I would like to thank the following students in the Department of Speech Pathology and Audiology, University of the Witwatersrand for their co-operation, enthusiasm and suggestions: Misses F. Janks, C. Linton, N. Moss, Y. Sarfin, B. Shakinovsky and M. Weinberg.

My colleague, Mrs M. Noach, gave many suggestions, especially with regard to the habit breaker plate.

\section{REFERENCES}

1. Carrell, J.A. (1968) Disorders of Articulation. Foundation of Speech Pathology Series. Prentice Hall.

2. Deutsch, M. (1954) The effects of co-operation and competition upon Group Process in D. Cartwright and A. Zender, Eds. Group Dynamics Reseurch and theory. Tavistock Publications Ltd.

3. Ehrlich, Ann Beard (1970) Training Therapists for Tongue Thrist Correction. Charles C. Thomas.

4. Fletcher, S.G., Casteel, R.L. and Bradley, D.P. (1961) Tongue thrust Swallow, Speech Articulation and Age.J. Speech Hearing Dis., 26, 201-208. 
5. Gardiner, M.D. (1935) The Principals of exercise Therapy. G. Bell and sons Limited.

6. Hanson, M.L. (1967) Some Suggestions for more effective therapy for tongue thrust. J. Speech and Hearing Dis., 32, 75-79.

7. Knott, M. and Voss, D.E. (1968) Proprioceptive Neuromuscular Facilitation Patterns and techniques, 2nd Ed. Harper \& Row.

8. MacDonald, E.T. (1967) Articulation Testing and Treatment: A sensory Motor Approach, Stanwix House, Inc., Pittsburgh.

9. Mims, H.A., Kolas, C. and Williams, R. (1966) Lisping and Persistent thumb-sucking among children with open bite malocclusions. J. Speech Hearing Dis., 31, 176-178.

10. Overstake, C.P. (1970) An investigation of tongue thrust swallowing and the functional relationship of deviant swallowing, Orthodontic problems and Speech defects. ASHA National Convention.

11. Rogers, J.H. (1961) Swallowing patterns of a normal population sample compared to those of patients from an orthodontic practice. Amer. $J$. Ortho., 47, 674-689.

12. Rood, M.S. (1956) Neurophysiological Mechanisms Utilised in treatment of neuromuscular dysfunction. Amer. J. of Occ. Therapy, 4, No.2, pp 220 et seq.

13. Salzman, J.A. (1971) Training Therapists for Tongue Thrust Correction. Book Review. Amer. J. Ortho., 59, p.411.

14. Shelton, R.L. (1963) Therapeutic Exercises and Speech Pathology. ASHA, 5, 855.859.

15. Straub, W.J. (1961) Malfunction of the tongue Part Il. The abnormal swallowing habit. Its causes, effects and results in relationship to orthodontic treatment and speech therapy.Amer. J. Orth., 47, 596-617.

16. Straub, W.J. (1962) Mal function of the tongue Part III. Amer. J. Orth., $48,486-503$.

17. Subtelny, J. Daniel and Subtelny, Joanne E. (1962) Malocclusion, Speech \& Deglutition. Amer. J. Orth., 48, 685-697.

18. Wood, J.M. (1971) Tongue thrusting, Some Clinical Observations. J. Speech Hearing Dis., 36, 82-89. 